\title{
Successful Transcatheter Closure of a Rare Coronary-Pulmonary Artery Fistula Causing Reversible Myocardial Ischemia and Heart Failure: Report of a Case
}

\author{
Umut Kocabas ${ }^{1 *}$ and Mustafa Akin ${ }^{2}$ \\ ${ }^{1}$ Department of Cardiology, Edremit State Hospital, Turkey \\ ${ }^{2}$ Department of Cardiology, Ege University School of Medicine, Turkey
}

Submission: March 19, 2017; Published: June 05, 2017

*Corresponding author: Umut Kocabas, Department of Cardiology, Edremit State Hospital, Balikesir, 10300, Turkey, Tel: +90 5079974999 ; Fax: +90 26637313 13; Email: umutkocabas@hotmail.com

\begin{abstract}
Coronary artery fistula is a rare, abnormal fistulous communication between a coronary artery and a cardiac chamber or large vessel. Being mostly asymptomatic, coronary artery fistula can seldom cause myocardial ischemia, heart failure, arrhythmias and infective endocarditis. We present you a case of coronary-pulmonary artery fistula causing reversible myocardial ischemia and heart failure which is successfully treated by transcatheter coil embolisation method.
\end{abstract}

Keywords: Heart failure; Coronary artery fistula; Coronary anomaly; Coil embolisation; Myocardial ischemia

\section{Introduction}

Coronary artery fistulas (CAFs) are anomalous terminations of coronary arteries in cardiac chambers or great arteries created by bypassing the myocardial capillary bed [1]. CAFs are rare and mostly asymptomatic. However, hemodynamically significant CAFs may cause myocardial ischemia, congestive heart failure, arrhythmias and infective endocarditis [2,3]. We present a case of coronary-pulmonary artery fistula causing reversible myocardial ischemia and heart failure that was successfully treated with transcatheter coil embolization.

\section{Case Report}

A 24-year-old woman was referred to our cardiology outpatient clinic with symptoms of shortness of breath and angina. Her electrocardiogram showed T-wave inversion in the precordial leads. Transthoracic echocardiography showed mild hypokinesia in the left ventricular anterior wall, and the modified Simpson's method revealed that her left ventricular ejection fraction (LVEF) was 49\%. Using myocardial perfusion scintigraphy, we detected an apical hypoperfused area and determined that her LVEF was 46\%. Coronary angiography (CAG) revealed no obstructive coronary lesions; however, a fistula was observed between the left anterior descending (LAD) artery and the pulmonary artery (Figure 1). Closure of the fistula was planned because the patient was symptomatic with ischemia determined by electrocardiography, scintigraphy and echocardiography. Percutaneous intervention was performed and a 8-French Judkins Left 4.0 coronary guiding catheter was inserted into the right femoral artery and engaged into the left main coronary artery.

The fistula was selectively catheterized with a 0.014-inch coronary guide wire and a microcatheter via the LAD artery and successfully embolized with detachable coils (two coils sized $2 \mathrm{~mm} \times 2 \mathrm{~cm}$, two coils sized $2 \mathrm{~mm} \times 3 \mathrm{~cm}$ and two coils sized $2 \mathrm{~mm} \times 4 \mathrm{~cm}$, Axium $^{\mathrm{TM}}$ Detachable Coil System). After $15 \mathrm{~min}$ of embolization, angiography showed a thrombosed fistula with distal thrombolysis in myocardial infarction 0 flow (Figure 2). 
No post-procedural complications developed. A week after the procedure, electrocardiography revealed nonspecific ST-T segment changes, myocardial perfusion scintigraphy revealed no left ventricular infarction or ischemia, and the patient's LVEF was 50\%. The patient discharged from the hospital. At her 6-month follow-up visit, she was totally asymptomatic and electrocardiography was normal. Echocardiography showed normal systolic function, and her LVEF was calculated as $57 \%$ with the modified Simpson's method.

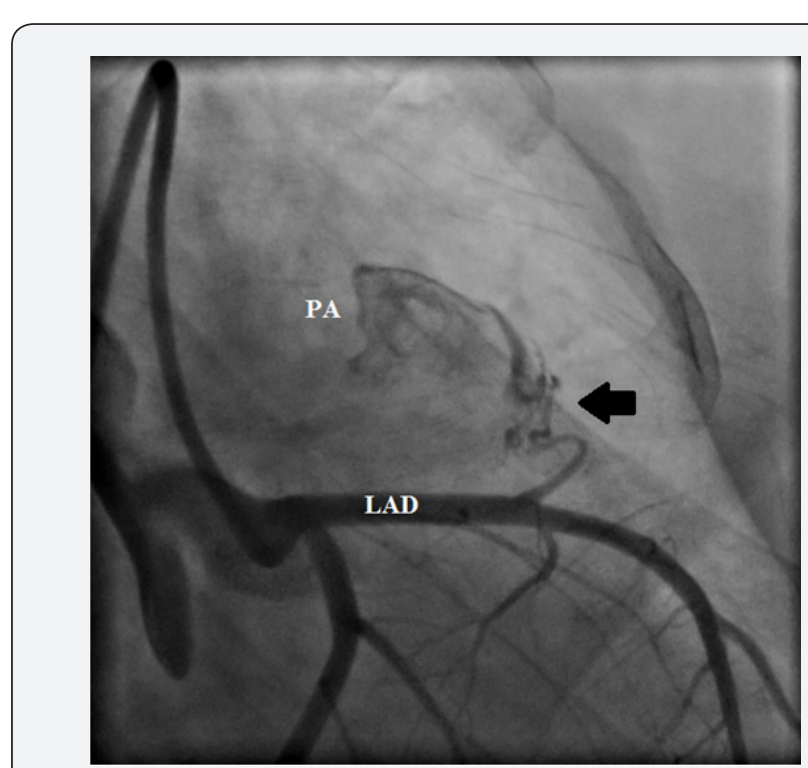

Figure 1: Coronary angiogram view from right caudal position showing fistula (arrow) between left anterior descending artery and pulmonary artery (LAD: Left Anterior Descending Artery, PA: Pulmonary Artery).

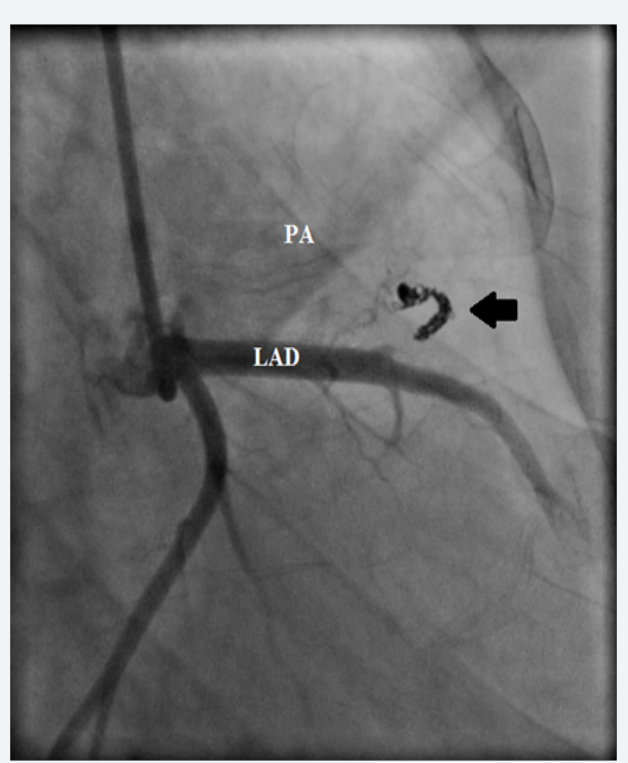

Figure 2:Trombosed fistula after coil embolization and TIMI -0 distal flow (arrow) LAD: Left Anterior Descending Artery, PA: Pulmonary Artery, TIMI: Thrombolysis In Myocardial Infarction.

\section{Discussion}

CAFs are anomalous terminations of coronary arteries in cardiac chambers or great arteries created by bypassing the myocardial capillary bed. CAFs are the second most common coronary anomaly after coronary artery origin anomalies [1]. CAFs represent $0.2-0.4 \%$ of all congenital coronary artery anomalies [4]. Rarely, they can reasons have acquired causes such as Takayasu arteritis or trauma [5,6]. CAFs mostly originate from the right coronary artery system and drain through the right heart chambers. A total of $25 \%$ CAFs originate from the left coronary artery system [7]. Pulmonary arterial fistulization is $17 \%$ in single $\mathrm{CAF}$, whereas this rate increases to $56 \%$ in bilateral CAF $[8,9]$. Being mostly asymptomatic, CAFs is usually suspected by hearing a murmur during a physical examination and is diagnosed in further evaluation or incidentally in diagnostic CAG. Hemodynamically significant fistulas can cause symptoms such as angina or dyspnoea. Angina and dyspnoea are usually associated with coronary steal phenomenon. In this phenomenon, coronary blood flow is shifted to the territory of the fistula because of low blood pressure in the diastole. Consequently, sufficient blood supply cannot be delivered and ischemia occurs in the distal territory of the fistula-bearing artery [1]. Complications associated with CAFs are myocardial ischemia, heart failure, arrhythmias, infective endocarditis, coronary thrombosis, aneurysm and/or rupture. Aging increases the risk of dilatation and/or aneurysm formation of the fistula, thereby increasing the risk of complications. The incidence of symptoms or complications in individuals $<20$ years is $19 \%$, and increases to $55 \%$ years after that age [10]. Asymptomatic and small-diameter CAFs to must be followed medically. The main indications for surgical or interventional treatment of CAFs are hemodynamically important fistulas, symptomatic status, myocardial ischemia, heart failure, arrhythmias, or infective endocarditis $[2,3]$. The main purpose of treatment is closure of the fistula without damaging coronary blood flow. Surgical therapy or transcather coil embolization, which is currently in wider use, can be performed. The efficacy of transcatheter coil embolization is similar to surgical therapy in terms of morbidity and mortality rates [2]. However, this method is superior to surgical therapy according to patient comfort and duration of hospitalization. Surgery is performed in patients who cannot undergo transcatheter coil embolization. In our patient, a fistula between the LAD and pulmonary arteries causing myocardial ischemia and heart failure was successfully treated with percutaneous transcatheter coil embolization. In conclusion; hemodynamically significant CAFs may cause myocardial ischemia and heart failure. Anatomically suitable cases can be treated with transcatheter coil embolization.

\section{Conflict of Interest}

We have no commercial, financial, and other relationships in any way related to the subject of this article that might create any potential conflict of interest. 


\section{References}

1. Levin DC, Fellows KE, Abrams HL (1978) Hemodynamically significant primary anomalies of the coronary arteries. Angiographic aspects. Circulation 58(1): 25-34.

2. Gowda RM, Vasavada BC, Khan IA (2006) Coronary artery fistulas: clinical and therapeutic considerations. Int J Cardiol 107(1): 7-10.

3. Kocabas U, Kaya E, Akin M (2016) Coronary injection ventriculography: Multiple coronary-cameral fistulas as a rare cause of stable angina pectoris. Int J Cardiol Acad 2(2): 68-70.

4. Yamanaka O, Hobbs RE (1990) Coronary artery anomalies in 126595 patients undergoing coronary arteriography. Cathet Cardiovasc Diagn 21(1): 28-40.

5. Said SA, van der Werf T (1999) Acquired coronary cameral fistulas: are these collaterals losing their destination? Clin Cardiol 22(4): 297-302.

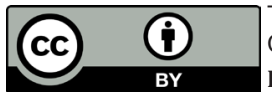

This work is licensed under Creative Commons Attribution 4.0 License

DOI: $10.19080 /$ JOCCT.2017.05.555670
6. Ercan E, Tengiz I, Yakut N, Gurbuz A, Bozdemir H, et al. (2003) Takayasu's arteritis with multiple fistulas from three coronary arteries to lung paranchima. Int J Cardiol 88(2-3): 319-320.

7. Fernandes ED, Kadivar H, Hallmann GL, Reul GJ, Ott DA, et al. (1992) Congenital mal formations of the coronary arteries: the Texas Heart Institute experience. Ann Thorac Surg 54(4): 732-740.

8. Bauer EP, Piepho A, Klövekorn WP (1994) Coronary arteriovenous fistula: surgical correction of a rare form. Thorac Cardiovasc Surg 42(4): 237-239.

9. Baim DS, Kline H, Silverman JF (1982) Bilateral coronary arterypulmonary artery fistulas. Report of five cases and review of the literature. Circulation 65(4): 810-815.

10. Sunder KR, Balakrishnan KG, Tharakan JA, Titus T, Pillai VR, et al. (1997) Coronary artery fistula in children and adults: a review of 25 cases with long-term observations. Int J Cardiol 58(1): 47-53.

\section{Your next submission with Juniper Publishers will reach you the below assets}

- Quality Editorial service

- Swift Peer Review

- Reprints availability

- E-prints Service

- Manuscript Podcast for convenient understanding

- Global attainment for your research

- Manuscript accessibility in different formats

( Pdf, E-pub, Full Text, Audio)

- Unceasing customer service

Track the below URL for one-step submission https://juniperpublishers.com/online-submission.php 